\title{
Subgingival Plaque Formation on Single and Polycrystal Aluminum Ceramics
}

\author{
Jun-ichi Otogoto, Shinichi Ebashi, Koji Tanaka, Kenji Fujikawa, Koichi Ito and Seidai Murai
}

(Received 19 May and accepted 10 June 1994)

Key words: single-crystal aluminum ceramic, polycrystal aluminum ceramic, subgingival plaque

\begin{abstract}
A study was conducted to investigate subgingival plaque formation on two types of dental implant material in the human oral cavity. Fifteen teeth affected by severe periodontitis and scheduled for extraction in five patients were selected. After thorough root planing, inlay cavities were prepared from the gingival margin to $5 \mathrm{~mm}$ subgingivally. Then, rectangular test specimens ( polycrystal aluminum ceramic ( $\mathrm{P}$ ), single-crystal aluminum ceramic ( S ) ) or a control dentin specimen ( D ) were installed in gold inlays, which were placed in the inlay cavities and left for 3,7 or $21 \mathrm{~d}$. As a consequence, $4 \mathrm{~mm}$ of the surface of each specimen was exposed to the environment of the periodontal pocket. After each test period, the specimens were removed from the inlays and examined by scanning electron microscopy ( SEM ).

The results suggested that $\mathrm{S}$ is a more suitable dental implant material than $\mathrm{P}$ from the viewpoint of clinical application because of its lower degree of plaque accumulation.
\end{abstract}

\section{Introduction}

Recently, various types of dental implant material have been used as abutments for prostheses used in the treatment of tooth loss. Brånnemark et al. ${ }^{[1]}$ obtained outstanding clinical results with osseointegrated root implants in a long-term follow-up, controlled study. However, some implants have to be removed frequently due to clinical symptoms such as gingival bleeding on probing, increased probing depth, suppuration and pain, similar to those seen in periodontitis around natural teeth. The initiation and progression of periodontitis-like breakdown around implant tissue remains to be elucidated and extensively investigat$\mathrm{ed}^{[2,3]}$. However, it seems likely that plaque accumulation around the dental implant transgingival area initiates gingival inflammation and leads to supportive tissue loss.

As bacterial plaque accumulation and qualitative changes in plaque affect the onset and progression of periodontitis, the microflora around healthy and failing titanium implants has been examined by a differential microscopy to identify bacterial morphotype ${ }^{[4]}$ and by culture ${ }^{[5]}$ to identify bacterial species.

In Japan, the most popular dental implant materials are single-crystal and polycrystal aluminum ceramics. However, to our knowledge, no studies of subgingival plaque formation on these two implant materials have been published. Therefore, we conducted the present study in order to observe sequential subgingival plaque formation on single-crystal and polycrystal aluminum ceramics in human subject using scanning electron microscopy ( SEM).

\section{Subjects}

\section{Materials and Methods}

Five systemically healthy patients ( males, aged 39 to 45 y ), who had been referred to the Department of Periodontology, Nihon University School of Dentistry, participated in the study. They all had at least three single-root teeth scheduled for extraction because of severe periodontal disease in the maxilla. They

音琴淳一, 江橋真一, 田中宏司, 藤川謙次, 伊藤公一, 村井正大

Department of Periodontology, Nihon University School of Dentistry

To whom all correspondence should be addressed: Dr. Jun-ichi Otogoto, Department of Periodontology, Nihon

University School of Dentistry, 1-8-13 Kanda-Surugadai, Chiyoda-ku, Tokyo 101, JAPAN 
had no history of serious illness and had received neither systemic antibiotic treatment in the previous 3 months nor adequate periodontal treatment. The nature of the study was explained to them, and informed consent was obtained.

\section{Test teeth}

Single-root teeth which met the following criteria were selected : 1) probing depth of $6 \mathrm{~mm}$ or more ; 2) bleeding on gentle probing ; 3) absence of caries on root surfaces ; 4) radiographic evidence of proximal bone loss; 5) no history of acute pain or swelling prior to the experimental procedure. Oral hygiene instruction was given and thorough root planing was carried out in each patient. Pulpectomy and root canal treatment of the experimental teeth were carried out under local anesthesia. One month after root planing, a total of 15 teeth which did not show gingival recession of $2 \mathrm{~mm}$ or more were selected for the study.

\section{Subgingival plaque formation on implant materials and human dentin}

A 4-mm-deep subgingival cavity from the gingival margin was prepared on the palatal surface of each experimental tooth. The gingival tissue was retracted far enough to avoid gingival injury and to secure the operation field. A final impression was made with silicone base impression material, and a subgingival gold cast metal inlay was fabricated on a plaster working model ( Figs. 1-A,C). Rectangular ( $2 \mathrm{~mm}$ x $6 \mathrm{~mm}$ x 1 $\mathrm{mm}$ ) single-crystal ( S ) and polycrystal ( P ) aluminum specimens were supplied by Kyocera Corp. (Kyoto, Japan ). Dentine (D) specimens, which were used as controls, were prepared as follows. Extracted impacted third molars were collected at the Department of Oral Surgery, placed in individual bottles and stored at $-20^{\circ} \mathrm{C}$ until required. They were then thawed, and the crown of each was cut off and discarded. All the cementum was removed using a \# 700 carbide burr fitted to high-speed handpiece, and root dentin specimen sections were cut. A groove was made on the pulp side of each dentin specimen to distinguish the experimental surface from the opposite side. The former was polished with \# 240 waterproof abrasive paper to make the surface roughness of the dentin surface as smooth as that after root planing. The metal inlay was placed in the prepared root cavity and fixed with temporary cement ( Fig. 1-B ).

Each specimen on the metal inlay protruded $2 \mathrm{~mm}$ into the oral cavity from the gingival margin and was inserted $4 \mathrm{~mm}$ into the subgingival pocket area. The coronal end of each specimen was reinforced with selfcuring resin to ensure that each specimen was placed securely. Each subgingival inlay with the designated specimen was kept on the assigned tooth for 3, 7 or $21 \mathrm{~d}$, and the patients were asked not to brush the experimental tooth. After each experimental period, the subgingival inlay was removed and the specimen was detached from the inlay carefully to avoid disturbing the formed plaque. The specimens were washed with sterile saline in a beaker. Each subgingival metal inlay was polished with a polishing brush and cleaned with an ultrasonic cleaner, and the experimental teeth were debrided with Gracy curettes and irrigated with saline ready for the next experimental period.

The implant specimens were fixed in $2 \%$ glutaraldehyde in cacodylate buffer $(\mathrm{pH} 7.0)$ for $2 \mathrm{~h}$ at $4{ }^{\circ} \mathrm{C}$, washed 3 times for $10 \mathrm{~min}$ each in this buffer, dehydrated in a graded series of aqueous ethanol for $10 \mathrm{~min}$ per concentration, then immersed in isoamylacetate. The specimens were critical-point dried, sputter-coated with gold, and examined and photographed with a scanning electron microscope ( SEM, JEOL T-100, Nihon Electronic, Tokyo, JAPAN ).

\section{SEM observations}

\section{1) Test specimens before oral exposure}

The surface morphologies of the three test specimens are shown in Fig. 2. The S specimen had a fairly flat and even surface ( Fig. 2A ), whereas the P specimen surface was composed of various-shaped crystals with 1 to 5 holes between them ( Fig. 2B ). The surface of the D specimen was even, and dentine tubule orifices were evident ( Fig. 2C). 


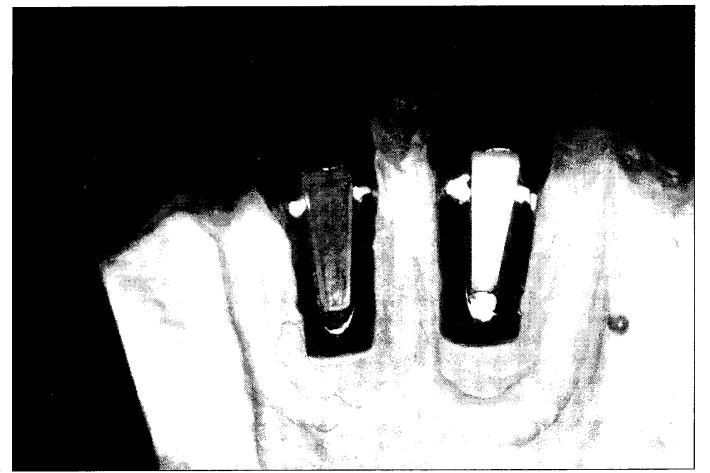

Fig. 1A Gold Cast metal inlay on working plaster model

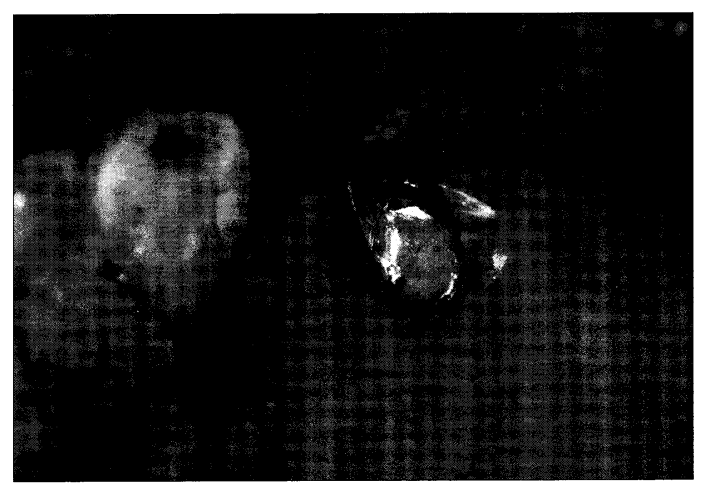

Fig. 1B The metal inlay placed in the oral cavity

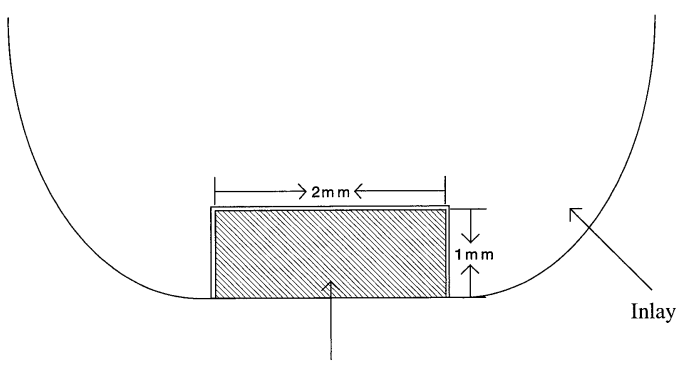

Specimen

Fig. 1C The specimen placed into the metal inlay

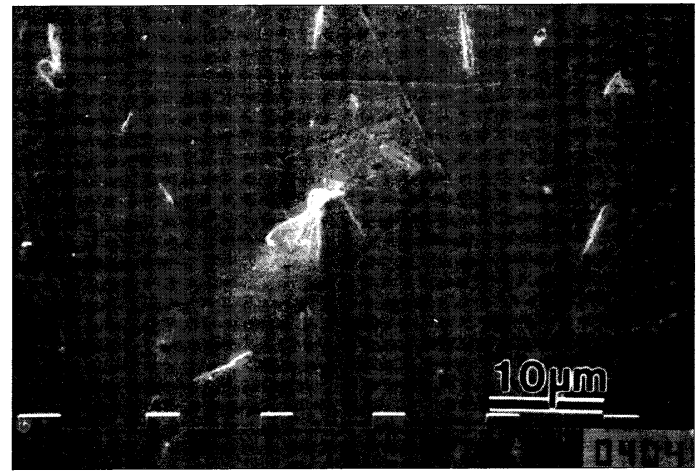

Fig. 2A S specimen (x2000)



Fig. 2B P specimen (x2000)

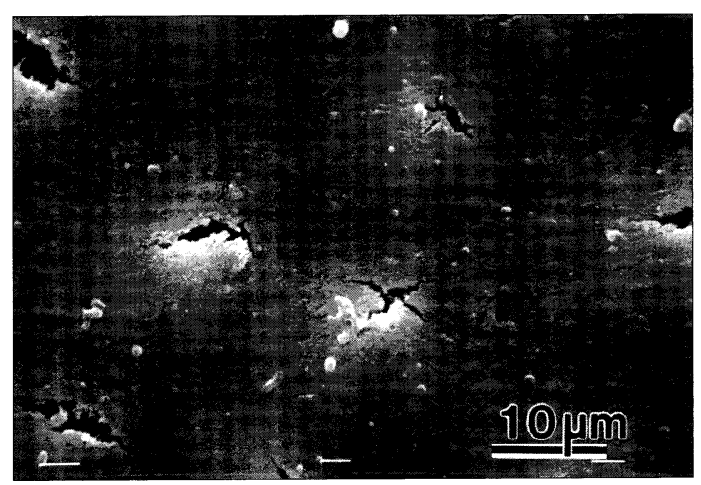

Fig. 2C D specimen (x2000)

Fig. 2 The surface of test specimen before oral exposure 


\section{2) Oral exposure for $3 \mathrm{~d}$}

Scattered cocci, rods, and small colonies of cocci were present on the S specimens (Fig. 3A ). A thick plaque layer composed of cocci, rods and filamentous bacteria covered the surface of the $\mathrm{P}$ specimens (Fig. 3B ). Monolayers of cocci were observed on the D specimen surface, and occasionally scattered rods were present on the coccoid colonies ( Fig. 3C ).

\section{3) Oral exposure for $7 \mathrm{~d}$}

On the S specimens, a monolayer of cocci and scattered rods were present ( Fig. 4A ). On the P and D specimens, mature plaque, comprising cocci, rods, and filamentous bacteria, had formed ( Figs. 4B,C ).

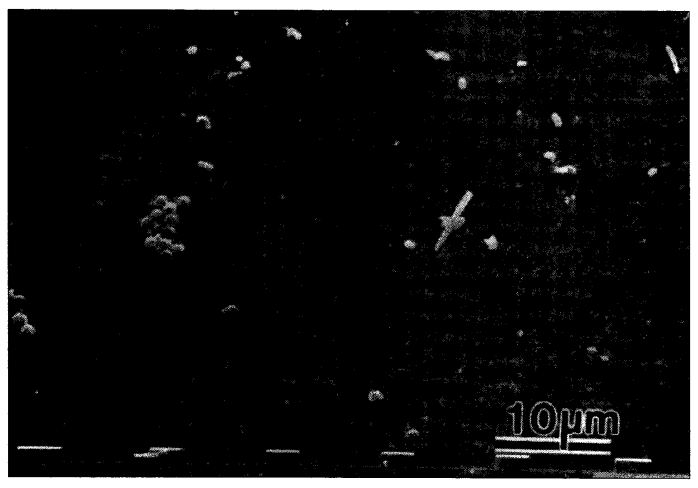

Fig. 3A 3 d exposure on S specimen (x2000)

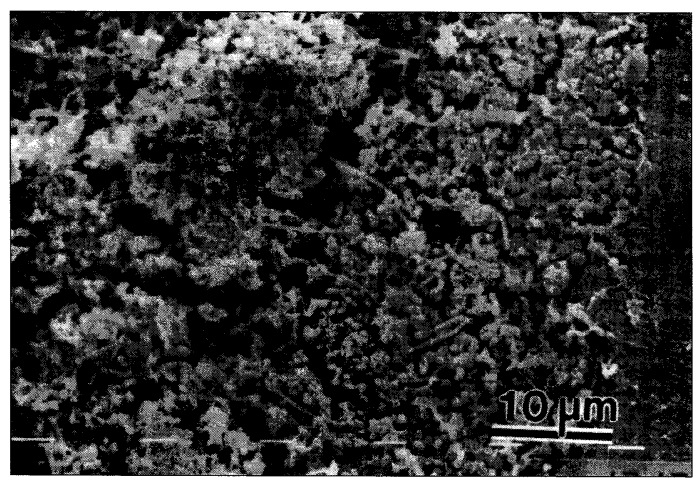

Fig. 3B 3 d exposure on $P$ specimen (x2000)

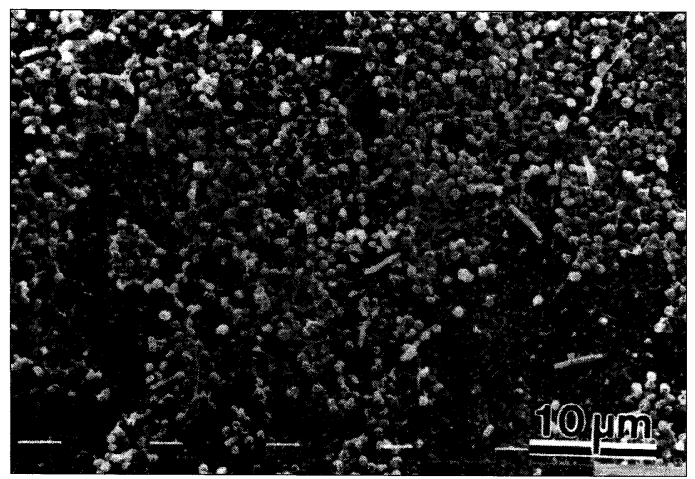

Fig. 3C 3 d exposure on D specimen (x2000)

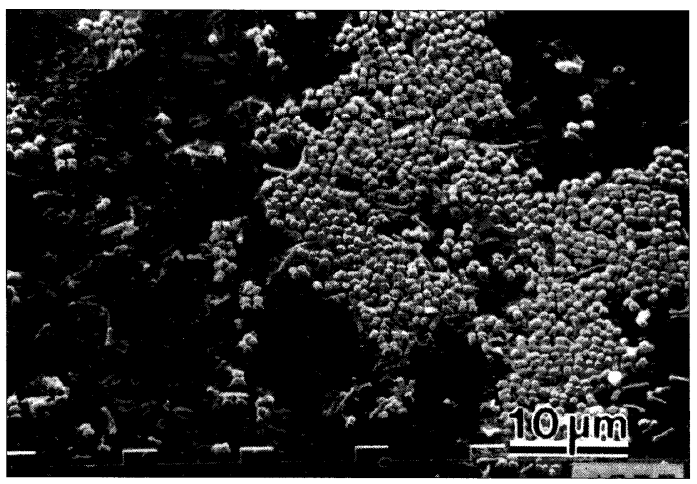

Fig. 4A $7 \mathrm{~d}$ exposure on $\mathrm{S}$ specimen (x2000)

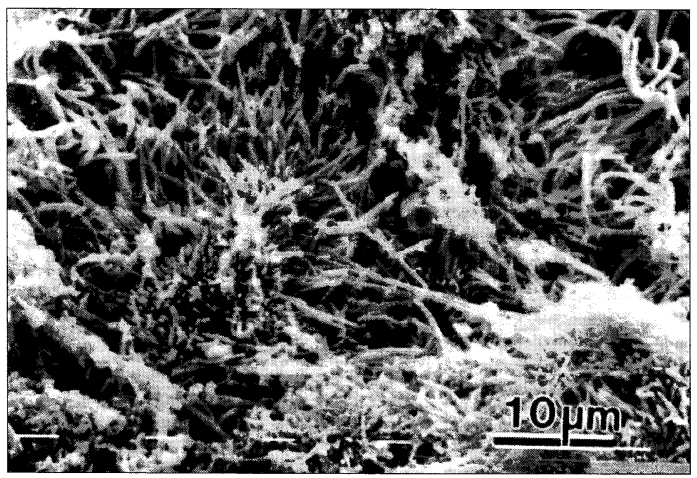

Fig. 4B $7 \mathrm{~d}$ exposure on $\mathrm{P}$ specimen (x2000)

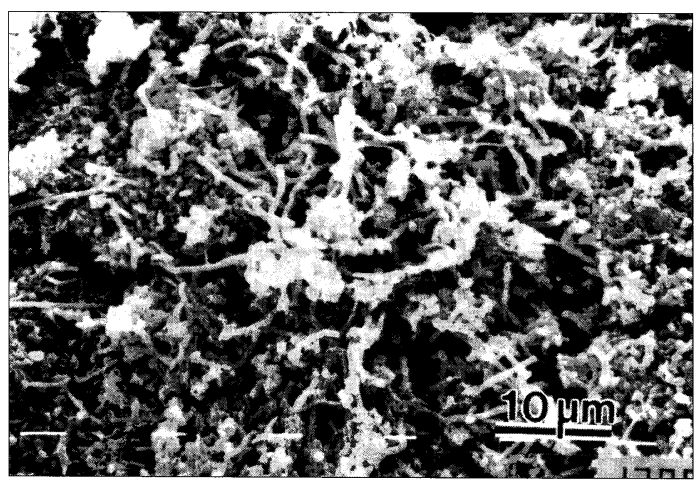

Fig. 4C $7 \mathrm{~d}$ exposure on D specimen (x2000) 
4) Oral exposure for $21 \mathrm{~d}$

A thin layer of plaque in which cocci were still the dominant bacteria, had formed on the $\mathrm{S}$ specimens ( Fig. 5A ), whereas thick, mature plaque covered the P and D specimen surfaces. The number of filamentous bacteria and aggregated cocci and rods attached to the thick filamentous bacteria had increased dramatically (Figs. 5B, C). Spirochetes and curved rods were encountered frequently ( Figs. 5D, E ).



Fig. 5A $21 \mathrm{~d}$ exposure on $\mathrm{S}$ specimen (x2000)

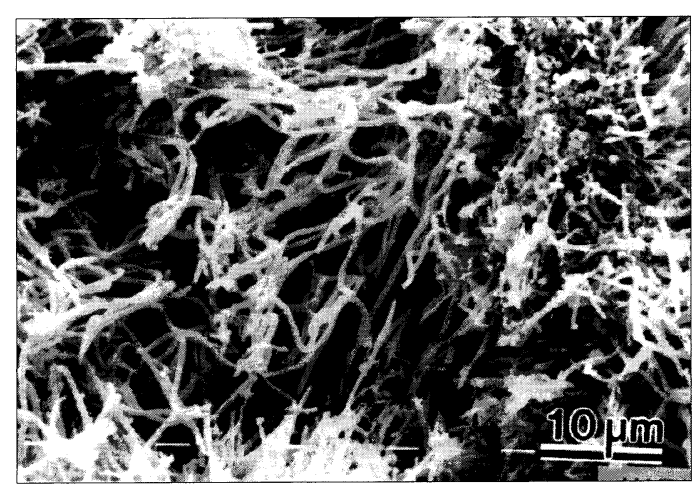

Fig. 5C 21 d exposure on D specimen (x2000)



Fig. 5B $21 \mathrm{~d}$ exposure on $\mathrm{P}$ specimen (x2000)

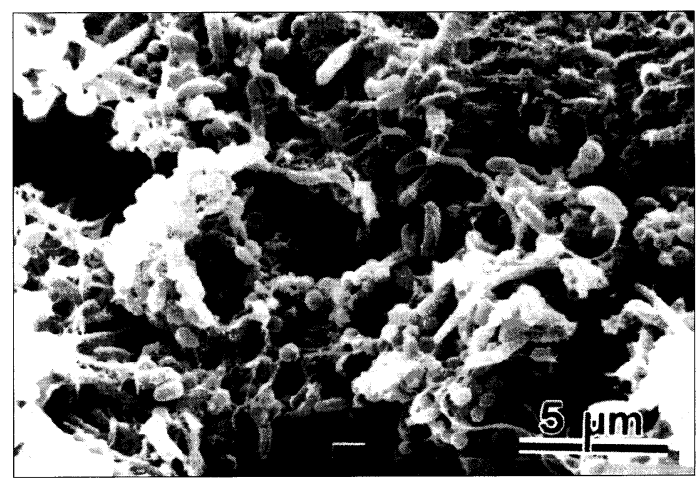

Fig. 5D $21 \mathrm{~d}$ exposure on $\mathrm{P}$ specimen (x5000)

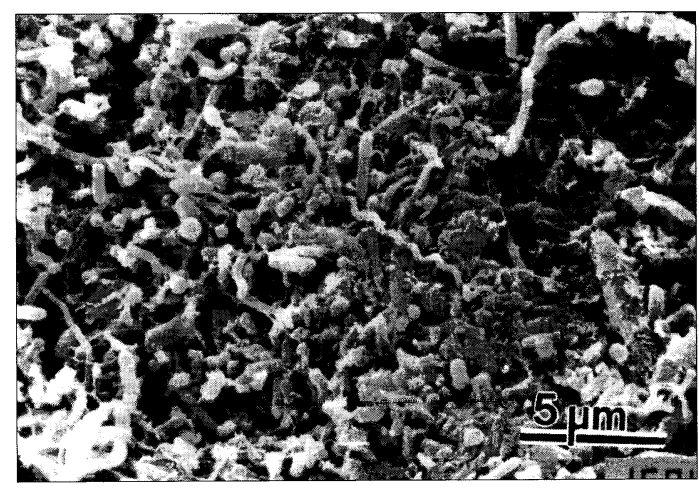

Fig. 5E $21 \mathrm{~d}$ exposure on D specimen (x5000) 


\section{Discussion}

Dental implants have been used for over $30 \mathrm{yr}$ for completely edentulous and partially edentulous patients. However, some implants have to be removed due to several complications. One major reason for fixture loss has been shown to be destruction of supportive tissue ( peri-implantitis ), similar to the periodontal breakdown that occurs around natural teeth ${ }^{[2,3]}$.

Within days, plaque accumulation on implant surfaces induces an inflammatory reaction, leading to destruction of the implant supportive tissue ${ }^{[6]}$. Therefore, the subgingival microflora around healthy and failing implants has been examined ${ }^{[4,5]}$. That around healthy implants was found to be identical to that of healthy natural teeth, whereas that around failing implants showed increased numbers of microorganisms considered to be periodontal pathogens. In studies that examined subgingival bacterial microflora by determining the bacterial morphotypes and identifying then using culture techniques, the bacteria accumulated around pure titanium osseointegration implants. However, in Japan, the materials most widely used for implants are aluminum ceramics, and there are very few reports about the supra- and subgingival microflora around such implants. Therefore, we investigated the sequential subgingival plaque accumulation and gingival inflammation on aluminum ceramic in vivo, using the inlay method developed by Konno ${ }^{[7]}$. However, this method involves inserting a foreign body into the subgingival area, which may irritate the periodontal tissue. During the 7-w experimental period, no detrimental symptoms, such as pocket deepening, bone loss, or abscess formation and exacerbation, were observed.

During the experimental period, the least supragingival plaque accumulation was observed on $\mathrm{S}$ specimens, compared with those on D and $\mathrm{P}$ specimens, in each subject.

$\mathrm{Ueki}^{\mathrm{ig}}$ reported that the different surface roughness of $\mathrm{P}$ and $\mathrm{S}$ influenced the attachment of $S$. mutans and $A$. viscosus in vitro. Such differences may explain the plaque accumulation on $\mathrm{S}, \mathrm{P}$ and natural teeth in vitro. The subgingival plaque observed on the $S$ specimens comprised coccoid cells throughout the experimental period, whereas that on $\mathrm{P}$ specimens comprised cocci, rods, and filamentous bacteria and, furthermore, spirochetes, which are considered to be intimately involved in periodontal disease.

The results of this study suggest that the quantity and quality of accumulated plaque on $\mathrm{S}$ specimens are more favorable to periodontal tissue than that which accumulates on $\mathrm{P}$ specimens.

\section{Conclusions}

The present results indicate that many bacteria considered to be periodontal pathogens accumulate on implant surfaces.

1) Subgingival plaque on the $S$ specimens comprised coccoid cells throughout the experimental period.

2) Subgingival plaque on the $P$ specimens comprised cocci, rods and filamentous bacteria and, at day 21 , spirochetes were observed frequently.

3) From the standpoint of subgingival plaque formation, it is evident that $\mathrm{S}$ is a more suitable material for dental implants than P. 


\section{References}

[ 1 ] Brånemark, P-I., Breine, U., Adell, R., Hansson, B.O., Lindstrom, J. and Ohlsson, A.: Intra-osseous anchorage of dental prostheses. I. Experimental studies, Scand. J. Plast. Reconst. Surg., 3, 81-100, 1969

[2] Lekholm, U., Adell, R. and Branemark, P. I.: Possible complications, In Tissue Integrated Prosthesis - Osseoinduration in Clinical Dentistry, 233-240, Branemark, E., Zarb, G. and Albecktsson, T., eds., Quintessence, Chicago, 1985

[ 3 ] Meffert, R.M.: Periodontal implication of endoosseous implants, In Periodontal Disease, 707-731, Schluger, S., Yuodelis, R., Page, R.C. and Johnson, R., eds., Lea and Febiger, Philadelphia, 1990

[4] Quirynen, M. and Listgarten, M.A.: The distribution of bacterial morphotypes around natural teeth and titanium implants admoudum Branemark, Clin. Oral Impl. Res., 1, 8-12, 1990

[ 5 ] Aspe, P., Ellen, R.P., Tverall, C.H. and Zarb, G.A.: Microbiota and crevicular fluid collagenase activity in the osseointegrated dental implant sulcus: A comparison of sites in edentulous and partially edentulous patients, J. Periodont. Res., 24, 96-105, 1989

[6] Hickey, J.S., O’Neal, R.A., Scheidt, M.J., Strong, S.L., Turgeon, D. and Vandyke, T.E.: Microbiologic characterization of ligature-induced peri-implantitis in the microswine model, $J$. Periodontol., 62, 548-553, 1991

[ 7 ] Konno, J. : A scanning electron microscopic study of subgingival plaque formation in patients with periodontitis, J. Jpn. Ass. Periodont., 25, 300-323, 1983 (in Japaneses)

[ 8 ] Ueki, T.: A study of bacterial adherence to the ceramic materials of dental implant, Nihon Univ. Dent. J., 60, 77-83, 1986 (in Japanese) 